\title{
Fluoride Measurement
}

National Cancer Institute

\section{Source}

National Cancer Institute. Fluoride Measurement. NCI Thesaurus. Code C122120.

The determination of the amount of fluoride present in a sample. 